\title{
Applied Anthropology in Juridical Grey Spaces
}

\section{Amanda J. Reinke}

\begin{abstract}
Aвstract: Informal justice refers to those legal practices that are traditionally outside the purview of formal law and legal systems. Since the advent of widespread social critique in the United States during the 1960s and 1970s, informal justice models have become increasingly popular and implemented in communities and within the legal system itself. The existence of informal justice mechanisms alongside and within formal justice systems in the US raises a number of questions for applied anthropologists interested in legal anthropology. In this article, I leverage four years of ethnographic fieldwork in the US to argue for the capacity of applied anthropologists to effectively work in grey juridical spaces that are beside and between the law, activism, and emerging bureaucratic regimes.
\end{abstract}

KEYWORDs: bureaucracy, informal justice, legal anthropology, restorative justice, United States

Inspired by powerful social critique in the 1960s and 1970s, diverse models of informal justice - those existing outside the normative purview of formal law and the legal system - have emerged in the United States. These models seek to combat and subvert the deleterious effects of a legal system considered costly and inefficient and which disproportionately affects racial and ethnic minorities, non-native English speakers, the LGBTQ community, and the urban and rural poor. Some informal justice mechanisms, such as alternative dispute resolution, have been supported by legal actors who have considered the justice system 'too costly, too painful, too destructive, too inefficient for a truly civilized people' (Burger 1984: 66), and have subsequently become incorporated into formal law and legal systems. Informal justice mechanisms encompass a wide array of practices and are presently implemented in diverse contexts, such as schools, courts, community organisations, and religious institutions. These practices and contexts are ideally envisioned as existing outside the purview of formal law and as thereby being divorced from the structural, bureaucratic, and physical violence that it causes in marginalised communities, examples of which include the schoolto-prison pipeline and mass incarceration (Calkins 2010; Kelly 2010; Kim 2011/2012; Wacquant 2000; Zehr 1990).

Regardless of philosophical and practical nuances, all informal justice models are imagined and defined as the antithesis of formal law and are ideally envisioned as highly responsive to participant needs, faster and more efficient, less harmful and more inclusive, and capable of providing healing for all parties rather than only punishing one party for harms (Merry and Milner 1995). For example, restorative justice (RJ) is predicated upon healing and the full and active participation of all parties in conflict (Zehr 1990). Practitioners emphasise the importance of skills-building with a firm foundation in principles and values, such as empathy, trust, honesty, and respect. As a result, RJ is typically used for non-violent civil conflicts, in correctional institutions for rehabilitation, and in schools for skills-building and peer-to-peer conflict management. Other models, such as community mediation, are based upon community-driven non-criminalising justice to resolve neighbour, tenant, and family disputes with an

Anthropology in Action, 26, no. 2 (Summer 2019): 1-8 @ Berghahn Books and the Association for Anthropology in Action ISSN 0967-201X (Print) ISSN 1752-2285 (Online) doi:10.3167/aia.2019.260201 
eye towards healing the community. Whereas formal legal mediation tends to be evaluative, wherein the mediator has much more control over the pace, process, and outcomes of the event, community mediation tends to be facilitative or transformative, whereby the mediator cedes some control over the pace, process, and outcomes to the participants (Reinke 2016).

Despite this initial imagining, diverse contemporary informal justice practices have complex and often symbiotic relationships with the very legal system whose violence they seek to mitigate. Some, such as victim-offender mediation, are often used exclusively within formal legal contexts, while other models, such as RJ, may be used in tandem with formal law or as an informal process that has no implications for formal judicial procedures. However, informal justice procedures and rituals are often derived from state law, and these cases are often overseen by the legal system. Laura Nader criticises informal frameworks that, from her perspective, exist as a 'coercive mechanism of pacification' (1993: 1). Informal frameworks trade justice for harmony and are promoted as regularised practices used by lawyers. The incursion of formal law and its actors into informal justice has led some scholars to claim that the latter is being colonised by formal law (Roche 2002) and question its ability to be implemented cross-culturally and in diverse contexts (Mohammad et al. 2019). Others, such as Lorig Charkoudian (2010), argue that the relationship between informal justice and formal law is mutually beneficial in its dependency: informal justice practitioners receive legitimacy with the public from their relationship with the state, while the state is reprieved from overburdened dockets. The resulting justice practices often conflate formal and informal mechanisms, which are often poorly integrated into a cohesive whole. This result is compounded by the dearth of data that could be used to advocate for a particular practice or implementation method. Where studies have produced data on informal justice programmes, the data is often rather simplistic and survey-based, failing to reflect the reality of this uneven and ever-changing justice landscape for affected communities.

In this article, I examine the ability of applied anthropologists to marshal ethnographic enquiry and infiltrate these contested juridical grey spaces, providing valuable insights into the intersections of the informal and formal legal realms. I draw on 14 months of ethnographic fieldwork in the San Francisco Bay Area (2014-2015) and one year of fieldwork in Richmond, Virginia (2016-2017), to illustrate the potential of applied anthropology in juridical grey space.

\section{Ethnographic Enquiry and Informal Justice}

In informal justice and conflict resolution literatures, there is little reflection on the work and life of the practitioners or disputants who inhabit the juridical grey space at the nexus of informal and formal justice practice. Research presents recipients of justice assistance as 'respondents' who are either satisfied or dissatisfied with programmes and services, whose disputes are resolved or unresolved, and who either saved money or not (Charkoudian 2010; Charkoudian and Wayne 2010; Gromet et al. 2012; Jeghelian et al. 2011; Sherman et al. 2015). There is little consideration of the challenging decisions that are being made and the challenging activities that are occurring amongst disputants who are accessing assistance for their case or for the practitioners who are providing it. In fact, this space, which is referred to by Andrew Woolford and Robert Ratner (2010) as the 'informal-formal justice complex', is presented as a realm of coexistence between state structures and actors, and informal justice practitioners who work together to redefine justice. They work in harmony to reach mutual goals. These conceptualisations lack nuanced understandings of the challenges, opportunities, and everyday work of informal justice from the perspectives of the practitioners, disputants, and the bureaucratic machinery (see Reinke 2016).

My fieldwork was conducted with individual practitioners and those who work within non-profit settings to offer informal justice services, as well as policy-makers and informal justice clients. Ethnographic findings from an applied anthropological perspective reveal the complexity of informal justice practitioners' relationship to the state. Ethnographic enquiry, a hallmark of political and legal anthropological approaches, is a powerful tool that illuminates the intricacies of everyday work, relationships, and violence. For example, anthropologist Sally Engle Merry's work with neighbourhood justice movements (1982) and on conflict and working-class awareness of justice processes (1990) illustrates the utility of ethnography for illuminating daily realities and struggles for justice. With regard to informal justice, engaging this methodological and analytical tool allows scholars such as Merry to analyse the intersection of formal and informal conflict resolution as a dynamic space, rather than as a quiet, passive space where quiet revolutionaries extend their forms of justice into the state structure.

Over the course of 14 months of fieldwork in the San Francisco Bay Area and one year of research in 
northern Virginia, ethnographic enquiry revealed the underlying tensions in informal justice practitioners' decision-making processes and their justice practices. I interviewed practitioners, policy-makers debating the implementation of informal justice within formal legal contexts, and clients; observed justice processes; and worked alongside practitioners to conduct case intake, assessment, and development for approximately two hundred cases. In both the Bay Area and Virginia, I investigated the interface between informal and formal legal work that is on the cutting edge of transformations within the justice system amidst social justice concerns. I then applied the data obtained so as to support strategic planning, grantseeking activities, and evaluations of programming in non-profit organisations and by practitioners.

In both research sites, the implementation of informal justice has proliferated alongside social justice movements. Social movements seeking to criticise and overturn cultures of legal violence and impunity while espousing the virtues of informal justice paradigms (e.g. Black Lives Matter) pervaded my field sites. Activists in Oakland chained themselves to the mass transit train system in protest at the physical and structural violence perpetrated by the formal legal system in their communities. Black Lives Matter activists instead initially called for paradigms, such as RJ, to promote equitable and meaningful justice in marginalised communities. As an applied legal anthropologist, I realized that this confluence of formal legal practice, social justice effort, and informal justice philosophy was an opportunity for me to carry out rich ethnographic research and to apply my knowledge and skills to a pervasive problem that affects the places in which I live and work.

Applied ethnographic research thus reveals the dynamic spaces of juridical flexibility wherein practitioners, legal actors, parties in conflict, and social justice crusaders are all actively working and leveraging paradigms and practices to meet their needs (Reinke 2016). Informal justice practitioners work against entrenched continuums of violence within the legal system to champion justice for their clients. Formal law and its practitioners simultaneously leverage informal justice practices and practitioners when it's considered useful, but may not share the same social justice goals. One informal justice practitioner and former lawyer working with juveniles in conflict with the law reflected on policy-makers' interest in juvenile social justice and mitigating the school-toprison pipeline as follows: 'Once they're locked up, honey, they don't care' [about the child] (Interview 2017; Reinke 2018a). Although client and practitioner narratives and quantitative results in terms of user satisfaction and recidivism may be pleasing for informal justice activists, interviews and observational interactions with informal justice practitioners reveal concerns. Practitioners do not believe that state actors are genuinely concerned with social justice efforts or the individuals whose lives are negatively affected by justice system processes and outcomes, such as fines and incarceration.

\section{Growing Pains in the Juridical Grey Space}

This nexus of informal-formal conflict resolution where informal and formal legal practitioners and practice meet is still a grey space: no one knows where the boundaries of one type of justice begin and end. No one knows the expectations and goals of judge, lawyer, disputant, informal justice practitioner, or advocate. Despite the rising interests in informal justice throughout the United States, there is still very little data (especially qualitative data) available on the efficacy, level of satisfaction, and longevity of informal justice, and there is very little data that indicates what type of relationship (if any) these programmes and processes should have with the formal legal structure. There is also very little data indicating what the everyday work and relationships are in this juridical grey space. The result is a convoluted landscape of seemingly random attempts at formulating informal justice within, beside, or completely separate from the state and a similarly convoluted landscape of data to support any particular resolution to this juridical quandary.

Practitioners bear the burden of navigating this absence of data even as they must marshal that data to make important decisions about their programmes and their relationship to the state. A practitioner in Virginia, for example, was concerned about the growing relationship between the non-profit organisation that she is affiliated with and the state. Memoranda of understanding (MOUs), bureaucratic documents which guide the parameters of these relationships, solidify this relationship, but also cause confusion amongst informal justice volunteers and paid practitioners (Reinke 2018b). This practitioner was particularly concerned that their MoU with the county would make them 'volunteers for the county, and not for [the nonprofit]'. She therefore thought that 'it's incumbent on us, before we start this [work], to have written rules, written guidelines' beyond the MOUs that further outline the relationship between the non- 
profit and the state (Interview 2017). The county had already retracted one MOU without clear cause and then claimed that the non-profit practitioners did not have appropriate clearance to work within the judicial sphere. These conflicts between informal justice non-profit organisations and the state are frequent, albeit poorly documented in scholarly debates. According to another practitioner working in northern Virginia, 'we've heard every story for six months that anyone could possibly fantasise' about why they cannot continue their work in the courts (Interview 2017). In interviews, practitioners reflected on these conflicts; even as they continued to formalise their relationship with the state via bureaucratic means (e.g. MOUs, case-referral processes), they distrusted the state's willingness to uphold these agreements. Furthermore, the time and energy required to manage bureaucratic relations with the state added to an already cumbersome case load for paid and volunteer practitioners. The lack of clarity in roles and responsibilities and this distrust added to the already confused justice landscape, as practitioners tried to advocate for their work within the formal legal system without any clear understanding of what relationships were effective in what contexts.

Ethnographic enquiry also illuminates the political economy of the juridical grey space where informal justice simultaneously is and is not accepted as part of the legal system. Where informal justice is ostensibly a separate, but overlapping, entity with the state, research demonstrates that the former and the latter are not truly separate. For example, many lawyers in the Bay Area have been trained by informal justice organisations such as San Francisco Community Boards and Restorative Justice for Oakland Youth. Lawyers take this training into the courtroom, mediation space, and consulting work, further muddying the juridical waters. One laywer reflected on their transition from the courtroom to informal justice practices; she was 'involved in the legal arena and just seeing, especially with juveniles, how they get caught up in that system and ... sort of get written off and just seeing that nobody was really looking at that whole child; they were just looking at that incident' (Interview 2017). Alternative justice advocates applaud the confluence of formal law and legal actors such as lawyers with informal justice, because it encourages the direct implementation of these practices within the legal system, ostensibly transforming it from within.

Additionally, many 'informal' or 'alternative' conflict resolution programmes and organisations actually receive over half of their funding from the state itself (Reinke 2016: 50). This funding often originates directly from state grants or legislation, such as the Dispute Resolution Protection Act in California. For example, during the 2014-2015 fiscal year San Francisco Community Boards - the first community mediation centre in the United States - received 55 per cent of its revenue from government grants. By contrast, donations received through its annual fundraising efforts accounted for only 17 per cent of its revenue (San Francisco Community Boards 2015). Further, during election seasons, non-profit organisations providing services to correctional centres, to juveniles in conflict with the law, or to neighbours with minor disputes are asked to support candidates publicly or introduce them as speakers during their events.

Many informal justice practitioners see this nexus and its associated political economy emerging and have come to believe that relevance and legitimacy for their practice is only attainable through the state. Despite their work to subvert the state, it is not uncommon for informal justice practitioners to actively seek out partnerships, MOUs, and other official relationships with the state. There is logic to their leveraging of the existing system for their paradigm's benefit. Informal justice is making inroads via collaborations with policy-makers, judges, lawyers, and other influential actors in the formal legal sector.

After years of working closely with policy-makers, alternative justice practitioners and advocates were rewarded when Virginia codified the use of informal justice for specific types of cases and at particular points in time during legal proceedings. In Virginia, restorative justice - a common type of informal justice that emphasises addressing needs and harms of all parties in conflict - can be enacted as part of probation or a suspended sentence, as a part of any juvenile's sentence (when not tried as an adult), to establish a victim-offender reconciliation programme, or as part of victim impact statements (Virginia State Crime Commission 2010). As a result, RJ organisations can ostensibly receive case referrals on a regular basis. It may also be easier for them to get access to legal spaces, such as the courtroom and the correctional institution, and those detained by the legal system, including juvenile offenders. However, in practice this is complicated by bureaucrats demanding that interventions be 'evidence-based'. Informal justice practitioners are uncertain what the evidentiary bar for 'successful' programmes and practices is and how to best prove their efficacy to the state. In Virginia, RJ programmes have come under fire in recent months for precisely this reason. Other states, 
such as California, also have similar laws for the use and introduction of informal justice procedures and conclusions in and into the court of law, although the specific parameters for what is deemed evidencebased will vary based on the judge's predilections and the lawyers' preferences.

While there is some rationality in using an existing system to advocate for and strengthen informal justice, the requisite amount of bureaucratic paperwork and time required to align informal justice with formal law is enormous. Informal justice is normatively handled by non-profits and non-governmental organisations that have limited staff, funds, and time, and that are often staffed by individuals with minimal experience working or collaborating with large bureaucratic institutions. The resulting alliance with formal law is often exhausting for many practitioners, many of whom are volunteers or work for little pay. Practitioners spend time travelling between various courts, schools, and conference rooms. They spend time filling out paperwork, filing casework, getting background checks and various identification card requirements, tracking funds, and maintaining relations with policy-makers, judges, lawyers, and police. This is all time that practitioners report could be used to focus on the communities and individuals that need their assistance (Reinke 2018b).

Practitioners are worried that all this time and energy will lead to justice practices that continue to exploit and marginalise normatively disempowered groups. In effect, they are concerned about becoming that which they seek to subvert. Collaborating with judges and lawyers requires working within the confines of the law - a system that has perpetuated violence on the marginalised communities that informal justice practitioners normatively work with. The result is widespread concern that working with formal law will mean that 'outsiders' such as policy-makers, judges, lawyers, or others, who may not have training in informal justice, will determine the practices, policies, and procedures that guide the practitioners' work. For these practitioners, it is often 'the idea that some entity who is not on the ground doing the work [that] would determine the best practices for the rest of us' who are practising informal justice on a daily basis (Hartman and Perloff 2015).

\section{Professionalising the Field}

On the ground, the answer to preventing the state from controlling informal justice processes and procedures has been a call to professionalise informal justice. Professionalisation entails a formal education gained through earning certain numbers of training hours, much like the Continuing Legal Education (CLE) credits that a lawyer must earn each year. Training costs money and time, which are both often prohibiting factors for low-income and marginalised groups (e.g. wage labourers, informal sector workers, those working multiple jobs). One practitioner in Virginia bemoaned the time and effort required to meet these standards: 'All of us who volunteer, I mean you have a snippet who are retirees, but then a lot of us have full-time jobs. And that's the thing, like my loyalty is always with the cause but it's like I always told you, I have bills to pay' (Interview 2017). The time and effort needed to meet requirements of professionalisation may be too cumbersome for practitioners, the majority of whom are volunteers or are paid very little.

It is important to note that these are groups considered potential clients for informal justice services and proceedings; in an ideal world, after having their dispute resolved they would then become practitioners themselves and thus bring back their knowledge and skills to their communities. However, costs for training are rising. In the Bay Area, a basic 40-hour course can cost over $\$ 800$ - ethnographic work reveals that this price is made necessary by the need for non-profits to meet the cost of rent, staffing, and other overhead costs related to operating in the region. This continued professionalisation may result in the creation of an educated elite class of justice practitioners mirroring the legal system's reliance upon lawyers and judges. This in turn would limit the ability of community members to become trained and to actively participate in the development of justice practices, policies, and procedures which directly (and disproportionately) affect them.

Conversely, some argue that professionalising the field could help ensure that practitioners are competent in their field. Professionalising sets a standard of education, expertise, and ability, and it defines who may or may not participate as a party. This may help efforts to formalise relationships with the state, thus providing guidance in what is currently an unclear and often tenuous relationship. According to one practitioner, frustrated with the lack of professionalisation and standardisation, 'we're not going to be deemed legitimate if we're homemakers and retired chaplains' (Interview 2017), but need to become professionals in a field of informal justice that is clearly defined and delineated. At one meeting of practitioners who work throughout northern California, the professionalism debate went back and forth, lasting 
over two hours and only coming to a close when the space reservation time had lapsed. I leaned over and asked a practitioner and friend whether this was a common debate, and he responded by rolling his eyes and reflecting that it continues on a regular basis and always surfaces when a regional meeting or group event is held. There is apparently no consensus on the matter.

Professionalisation is one attempt to become legitimate to policy-makers and the public, which shapes the level of engagement that the law and its actors are likely to have with informal justice. And while there are many informal justice advocates who champion this juridical grey space, there are also those who believe that working with the state is collusion. Practitioners worry that the problems pervading formal law and legal processes will also pervade their own work. As they attempt to resolve problems from within the system, transforming it from the inside out, they will in effect be enacting those problems within their own work and within themselves. This is especially true in my two field sites - the Bay Area and northern Virginia - where allegations of police brutality, gentrification of diverse neighbourhoods, and high rates of minority incarceration are all persistent problems. The stakes here are high. Practitioners implement their work in schools to mitigate the school-to-prison pipeline amongst disempowered and marginalised youth (Reinke 2018a). They work in prisons to reduce recidivism amongst adults and juveniles. They work in courtrooms as juvenile advocates and to provide alternatives to incarceration. Practitioners working in these two sites are knowledgeable about the widespread issues that marginalised communities face in confronting the legal system and want to make their services available in a wide array of sites and contexts. Thus, working with the legal system as professional informal justice mediators, advocates, and case workers provides a potentially productive opportunity to improve and support their communities.

\section{Conclusion}

What does the current state of contestation, debate, and messiness of informal justice mean for the future of the paradigm? While scholars debate the efficacy of informal justice as a separate or collaborative entity with the formal legal system, ethnographic data reveals that both practitioners and disputants themselves are unsure of what the future holds. For some, participating in informal justice processes was just one part of an overall awareness or life's effort to champion social justice issues in their communities. Thus, informal justice became an ideological platform to physically enact social justice through decision-making about a particular conflict. On the other hand, some parties bring their lawyer to informal justice sessions. In a handful of cases, I was not allowed to speak directly with the parties, but discussed scheduling and the dispute only with the lawyers acting on their clients' behalf. In the end, it appears as though most disputants are looking for a quicker, more effective, and cheaper resolution to their problems; any other benefit to their communities or to themselves is an additional bonus, but not necessarily a reason to work with informal processes rather than formal law. Ethnographic data here reveals the discrepancies evident between practitioners - seeking social justice outcomes at the community level and their clients - seeking effective and efficient noncriminalising solutions to pervasive problems that they experience as individuals.

Regardless of the multiplicity of opinions and perceptions on the ground, there is a seemingly inevitable march towards the integration of informal justice mechanisms and models into the formal legal system and the law. Virginia and California have already established some limited legal parameters regarding the use and introduction of informal justice in and into formal legal processes. Policy-makers are beginning to advocate for informal justice, especially for juveniles considered high risk for recidivism or for becoming trapped in a cycle of crime and poverty. According to one Virginia policy-maker, informal justice 'can work more efficiently with younger people, because it is forming behaviour, coping skills, and decision-making skills, [but] the politics of getting people on the same page [to implement programmes] is just as tricky as the implementation' (Interview 2017). The messy realities of professionalising and standardising the field and the bureaucratic necessities this creates are evident via ethnographic enquiry, and stand in stark juxtaposition to the official narratives citing the effects of informal justice on recidivism and satisfaction rates.

But whatever the outcome of all these debates and conflicts may be, while they exist in the juridical grey space it is clear that informal justice practitioners will have room for creativity and space to be flexible with individual, community, and legal needs on an ad hoc basis. Although some may worry about being 'homemakers' who are playing at the law, ethnographic enquiry reveals that the needs of practitioners, policy-makers, parties, and the general public are much 
more nuanced than overly simplistic debates about professionalisation or formal-informal collaboration. Instead, this is a juridical grey space where various actors compete and co-operate to determine and meet their needs and those of their community. In this grey space, applied anthropologists have the opportunity to deploy their skills as researchers both to analyse these bureaucratic processes and to identify challenges and potential mechanisms of overcoming challenges faced by non-profits, practitioners, and affected communities. For example, data from my fieldwork has been used to compile toolkits for best practices, rapid assessments, and final reports for non-profits that assist in strategic planning, organisational development, and grant-seeking practices. The juridical grey space where informal and formal law meet may be contested, debated, competitive, and cooperative, but it also opens opportunities for applied anthropologists to marshal both theoretical and practical skills to the improvement of their communities.

Amanda Reinke is Assistant Professor of Conflict Management at Kennesaw State University in Georgia. She is an applied legal anthropologist specialising in conflict resolution and peace-building in the United States and the African Great Lakes Region, especially amidst displacement. She conducts pro bono research for the Virginia Center for Restorative Justice. E-mail: areinke@kennesaw.edu

\section{References}

Burger, W. (1984), 'The State of Justice', American Bar Association Journal 70, no. 4: 62-66, https://www.jstor .org/stable/20757068.

Calkins, R. (2010), 'Mediation: The Radical Change from Courtroom to Conference Table', Drake Law Review 58: 357-399, https://lawreviewdrake.files .wordpress.com/2015/06/irvol58-2_calkins-2.pdf.

Charkoudian, L. (2010), 'Giving Police and Courts a Break: The Effect of Community Mediation on Decreasing the Use of Police and Court Resources', Conflict Resolution Quarterly 28, no. 2: 141-155, https://doi.org/10.1002/crq.20017.

Charkoudian, L. and E. Wayne (2010), 'Fairness, Understanding, and Satisfaction: Impact of Mediator and Participant Race and Gender on Participants' Perception of Mediation', Conflict Resolution Quarterly 28, no. 1: 23-52, https://doi.org/10.1002/ crq. 20011.
Gromet, D., T. Okimoto, M. Wenzel, and J. Darley (2012), 'A Victim-Centered Approach to Justice? Victim Satisfaction Effects on Third-Party Punishments', Law and Human Behavior 36, no. 5: 375-389, http://doi.org/10.1037/h0093922.

Hartman, M, and F. Perloff (2015), 'How Do We Encourage Good Restorative Justice Practice?', Zehr Institute for Restorative Justice Blog, 13 October, http://emu.edu/now/restorative-justice/2015/10/13/ how-do-we-encourage-good-restorative-justicepractice/.

Jeghelian, S., M. Palihapitiya, and K. Eisenkraft (2011), 'Legislative Study: A Framework to Strengthen Massachusetts Community Mediation as a Cost Effective Public Service' (Paper 1, Massachusetts Office of Public Collaboration Publications), http:// scholarworks.umb.edu/mopc_pubs/1.

Kelly, E. (2010), 'Philly Stands Up: Inside the Politics and Poetics of Transformative Justice and Community Accountability in Sexual Assault Situations', Social Justice 37, no. 4: 44-57, https://www.jstor.org/ stable/41478933.

Kim, M. (2011/2012), 'Moving Beyond Critique: Creative Interventions and Reconstructions of Community Accountability', Social Justice 37, no. 4: 14-35, https://www.jstor.org/stable/41478931.

Merry, S. (1982), 'Defining "Success" in the Neighborhood Justice Movement," in Neighborhood Justice: An Assessment of an Emergent Idea, (ed.) R. Tomasic and M. M. Feeley (New York: Longman), 172-192.

Merry, S. (1990), Getting Justice and Getting Even: Legal Consciousness among Working Class Americans (Chicago: University of Chicago Press).

Merry, S. and N. Milner (1995), The Possibility of Popular Justice: A Case Study of Community Mediation in the United States (Ann Arbor: University of Michigan Press).

Mohammad, T., A. Azman, and B. Anderstone (2019), 'The Global Three: A Malaysian Lens on the Challenges and Opportunities Facing Restorative Justice Planning and Implementation', Evaluation and Program Planning 72, no. 1: 1-7, https://doi.org/10.1016/j .evalprogplan.2018.09.007.

Nader, L. (1993), 'Controlling Processes in the Practice of Law: Hierarchy and Pacification in the Movement to Re-Form Dispute Ideology', The Ohio State Journal on Dispute Resolution 9, no. 1: 1-25, https://kb.osu.edu/ bitstream/handle/1811/79868/OSJDR_V9N1_001.pdf ?sequence $=1$.

Reinke, A. (2016), 'Advancing Social Justice through Conflict Resolution amid Rapid Urban Transformation of the San Francisco Bay Area' (PhD diss., University of Tennessee). 
Reinke, A. (2018a), 'Childhood and Restorative Justice in the United States', Neos 10, no. 1: 7-8, https:// www.researchgate.net/publication/323496388 Childhood_and_Restorative_Justice_in_the_United_ States.

Reinke, A. (2018b), 'The Bureaucratic Violence of Alternative Justice', Conflict and Society 4, no. 1: 135-150, https://doi.org/10.3167/arcs.2018.040111.

Roche, D. (2002), 'Restorative Justice and the Regulatory State in South African Townships', British Journal of Criminology 42, no. 3: 514-533, https://www .jstor.org/stable/23638879.

San Francisco Community Boards (2015), 'Share. Support. Sustain. Community Boards' Annual Report'. San Francisco, CA.

Sherman, L., H. Strang, E. Mayo-Wilson, D. Woods, and B. Ariel (2015), 'Are Restorative Justice Conferences Effective in Reducing Repeat Offending? Findings from a Campbell Systematic Review', Jour- nal of Quantitative Criminology 31, no. 1: 1-24, http:// dx.doi.org/10.1007/s10940-014-9222-9.

Virginia State Crime Commission (2010), 'Restorative Justice: Report Document No. 48' (Richmond, VA: Virginia State Crime Commission), https://rga.lis .virginia.gov/Published/2010/RD48/PDF.

Wacquant, L. (2000) 'America's New "Peculiar Institution": On the Prison as Surrogate Ghetto', Theoretical Criminology 4, no. 3: 377-389, https://doi.org/10.1177/ 1362480600004003007.

Woolford, A. and R. Ratner (2010), 'Disrupting the Informal-Formal Justice Complex: On the Transformative Potential of Civil Mediation, Restorative Justice, and Reparations Politics', Contemporary Justice Review 13, no. 1: 5-17, https://doi.org/10.1080/ 10282580903549094.

Zehr, H. (1990), Changing Lenses: A New Focus for Crime and Justice (Scottsdale, PA: Herald Press). 